\title{
Clinical prevalence of diseases and disorders in cattle and goat at the Upazila Veterinary Hospital, Beanibazar, Sylhet, Bangladesh
}

\author{
Arup Sen ${ }^{1 *}$, Samuel Muhit ${ }^{2}$, Rahul Das Talukdar Avi ${ }^{3}$, Razib Das ${ }^{4}$, Mahfuza Akther $^{5}$ and \\ Abdullah Al Mamun Shagar 6 \\ ${ }^{1}$ Department of Microbiology and Veterinary Public Health, Chittagong Veterinary and Animal Sciences University, Chittagong, \\ Bangladesh. \\ ${ }^{2}$ Department of Epidemiology and Public Health, Sylhet Agricultural University, Bangladesh. \\ ${ }^{3}$ Department of Environmental Sciences, Wageningen University \& Research Centre, Netherlands. \\ ${ }^{4}$ Upazila Livestock Office, Beanibazar, Sylhet, Bangladesh.
}

${ }^{5}$ Department of Pathology and Parasitology, Hajee Mohammad Danesh Science and Technology University, Dinajpur, Bangladesh. ${ }^{6}$ Department of Animal Science and Animal Nutrition, Chittagong Veterinary and Animal Sciences University, Chittagong, Bangladesh.

${ }^{*}$ Corresponding author. Email: arup09dvm@gmail.com. Tel: +8801812716471.

Authors contribution: All authors contributed equally and approved the final manuscript.

Copyright (C) 2018 Sen et al. This article remains permanently open access under the terms of the Creative Commons Attribution License 4.0, which permits unrestricted use, distribution, and reproduction in any medium, provided the original work is properly cited.

Received 13th December, 2017; Accepted 10th January, 2018

\begin{abstract}
The present study aimed to determine clinical prevalence of diseases and disorders in cattle and goat at the Upazila Veterinary Hospital, Beanibazar, Sylhet district of Bangladesh from August 2016 to July 2017. A total of 988 clinical cases (683 cattle and 305 goats) were recorded and analyzed. Each clinical case was diagnosed on the basis of general examination, clinical examination, microscopic examination and using common laboratory techniques. The clinical cases were categorized into three categories based on the treatment required (Medical, Gynaeco-obstetrical and Surgical). Among the clinical cases, highest percentage was found for medical (cattle $86.82 \%$ and goats $95.41 \%$ ) followed by surgical (cattle $7.47 \%$ and goats $4.26 \%$ ) and gynaeco-obstetrical (cattle $5.71 \%$ and goats $0.33 \%$ ). Within the medical cases, gastrointestinal nematodiasis (cattle $15.96 \%$ and goats $14.75 \%$ ) and digestive disorder or diarrhea (cattle $13.62 \%$ and goats $12.79 \%$ ) were recorded as main diseases in cattle and goats. On the other hand, gynaeco-obstetrical and surgical cases were found as significant ( $<3 \%$ in each occurrence). The current investigation could be helpful in designing control measures for the prevalent diseases.
\end{abstract}

Key words: Cattle, clinical prevalence, diseases and disorders, goat.

\section{INTRODUCTION}

Bangladesh is an agrarian economy where most of the people depend on the mixed farming system for their livelihood under rural condition. Geo-climatic conditions prevalent and traditional livestock rearing practices in the country side favoured the increased incidence of economically significant diseases in animals. The veterinary hospital is an ideal and reliable source of information about animal diseases and their treatment. People of the surrounding local areas bring their sick animals every day in the veterinary hospital to treat diseased conditions. It is important to know the disease occurrence pattern to resolve the problems in the local area via clinical records of the veterinary hospital. Previous reports on clinical case records from Mymensingh (Samad, 2001; Samad et al., 2002), Haluaghat Upazila Veterinary Hospital, Mymensingh (Sarker et al., 1999), Dairy Cooperatives in Pabna district (Pharo, 1987), Ulipur Upazila Veterinary Hospital, Kurigram (Kabir et al., 2010), 
Chandanaish Upazila of Chittagong district, Bangladesh (Pallab et al., 2012) and Patuakhali Science and Technology University Veterinary Clinic (Rahman et al., 2012) give information on commonly occurring disease conditions in rural areas of Bangladesh. Therefore, the objective was to determine the clinical prevalence of diseases and disorders in cattle and goats at the Upazila Veterinary Hospital, Beanibazar, Sylhet, Bangladesh.

\section{MATERIALS AND METHODS}

This study was performed at the Upazila Veterinary Hospital, Beanibazar, Sylhet during the one-year study period from August 2016 to July 2017. The necessary information and data were collected from registered record book of the veterinary hospital where all diseased cattle and goats were brought for treatment. After visual examination of the patient different parts and system of the body of each of the sick animals were examined by palpation, percussion, auscultation, needle puncture and gait and posture of the animals. The general clinical examination was conducted according to the merit of the individual case, on the basis of disease history and owner's complaint, symptoms and techniques such as microscopic examination and laboratory common techniques that are used (Rosenberger, 1979; Samad et al., 1988). Therefore, the temperature, pulse, and respiratory rate from each of these sick animals were recorded. Clinical examinations of all 988 animals (cattle 683 and 305 goats) were conducted on the basis of diseases history, owner complaint, symptoms, to diagnose the following diseases. These recorded clinical cases were categorized into three groups on the basis of treatment required. These groups were: (1) Medical cases (2) Gynaeco-obstetrical cases, and (3) Surgical cases. Pink eye was included under medical cases instead of surgery of eye diseases because surgical intervention has never been practiced in Bangladesh (Osmani et al., 2000). Obtained data were imported to the Microsoft Office Excell-2007 and transferred to the software STATA/IC-11 for analysis.

\section{RESULTS AND DISCUSSION}

From the obtained record of the clinical cases of animals that were treated, out of the total 683 cattle $86.82 \%$ has medical, $5.71 \%$ gynaeco-obstetrical and $7.47 \%$ surgical cases (Table 1). Among 305 goats, $95.41 \%$ had medical, $0.33 \%$ gynaeco-obstetrical and $4.26 \%$ surgical problems (Table 1). A previous study reported similar to this study were $84.1 \%$ medical, $4.7 \%$ gynaeco-obstetrical and $11.2 \%$ surgical cases in cattle; $81.0 \%$ medical, $1.1 \%$ gynaecoobstetrical and $17.9 \%$ surgical cases in goats were recorded in Patuakhali Science and Technology University
Veterinary Clinic, Babugonj, Barisal (Rahman et al., 2012). Another study revealed $90.76 \%$ medical, $5.46 \%$ gynaecoobstetrical and $3.78 \%$ surgical cases in cattle; $76.91 \%$ medical, $3.67 \%$ gynaeco-obstetrical and $19.42 \%$ surgical cases in goat during 1999 to 2001 from the Bangladesh Agricultural University (BAU) Veterinary Clinic, Mymensingh (Samad, 2001). On the other side, an overall comparison of affected cattle and goats based on gender (male and female) shows that in case of cattle male and female ratio of getting the disease is almost same in that local area (Table 2). This may be due to exposure of same environmental factors on that area. Study exhibits $50.51 \%$ male cattle and $49.49 \%$ female cattle affected by different diseases during one year round. On the other hand, goats males were affected slightly more than female (54.43\% male and $45.57 \%$ female) in the same year (Table 2). Another study that was conducted earlier shows disparity with these findings as female were found to be more susceptible to disease than male at Upazila Veterinary Hospital, Ulipur, Kurigram district, Bangladesh (Kabir et al., 2010).

\section{Medical cases}

Clinical cases record of fever with unknown etiology revealed that $7.8 \%$ cattle and $12.7 \%$ goats were affected. The percentages of occurrence of fever in this study is similar to the other reports of 5.1 to $12.1 \%$ cases of fever in cattle (Samad, 2001; Samad et al., 2002; Rahman et al., 2012) and 4.4 to $10.37 \%$ fever cases in goats (Hoque and Samad, 1997; Rahman et al., 2012; Alam et al., 2015). Anorexia due to unknown cause was reported in $1.76 \%$ cattle and $10.16 \%$ in goats (Table 1 ). Anorexia syndrome is the most common ailment among the non-specific clinical entities in routine ruminant practice (Prasad et al., 1980). Bloat is dietary in origin and most frequent case in ruminants in Bangladesh (Sutradhar et al., 2000). This study recorded $2.78 \%$ cases of bloat in cattle and $2.95 \%$ in goats (Table 1). Earlier findings reported $2.2 \%$ bloat in cattle and $2.5 \%$ in goats (Rahman et al., 2012) and 1.83\% prevalence of bloat in cattle and $3.98 \%$ in goats (Samad, 2001). Digestive disorders were found $13.62 \%$ and $12.79 \%$ in cattle and goats respectively to be high in occurrence (Table 1). The present study could be compared to the $11.5 \%$ of non-specific diarrhea in cattle (Kabir et al., 2010) and $12.23 \%$ in goats (Hoque and Samad, 1996, 1997). Inflammation of intestine with the evacuation of blood and mucus contained feces accompanied by tenesmus and colic is termed as Dysentery. This disorder was recorded in $1.32 \%$ cattle and $1.64 \%$ goats (Table 1 ). Other study reported $1.76 \%$ and $1.87 \%$ dysentery in cattle and goats (Samad, 2001). Pneumonia recorded in cattle and goats were $0.88 \%$ and $4.92 \%$, respectively (Table 1 ) where earlier recorded $5.1 \%$ and $16.8 \%$ cases of pneumonia in cattle and goats 
Table 1. Clinical Prevalence of diseases and disorders in Cattle and Goats recorded at Upazilla Veterinary Hospital, Beanibazar, Sylhet, Bangladesh.

\begin{tabular}{|c|c|c|c|c|c|}
\hline \multirow[b]{2}{*}{$\mathrm{S} / \mathrm{N}$} & \multirow[b]{2}{*}{ Diseases/Disorders } & \multicolumn{2}{|c|}{ Cattle $(n=683)$} & \multicolumn{2}{|c|}{ Goats $(n=305)$} \\
\hline & & $\begin{array}{c}\text { No. of affected } \\
\text { cattle }\end{array}$ & $\begin{array}{c}\text { Percentages } \\
(\%)\end{array}$ & $\begin{array}{c}\text { No. of } \\
\text { affected goats }\end{array}$ & $\begin{array}{c}\text { Percentages } \\
(\%)\end{array}$ \\
\hline \multicolumn{6}{|c|}{ Medical Cases } \\
\hline 1 & Bloat & 19 & 2.78 & 9 & 2.95 \\
\hline 2 & Digestive Disorder (Diarrhea) & 93 & 13.62 & 39 & 12.79 \\
\hline 3 & Fever & 78 & 11.42 & 55 & 18.03 \\
\hline 4 & Anorexia & 12 & 1.76 & 31 & 10.16 \\
\hline 5 & Dysentery (Coccidiosis) & 9 & 1.32 & 5 & 1.64 \\
\hline 6 & $\begin{array}{l}\text { Respiratory Disorder } \\
\text { (Pneumonia) }\end{array}$ & 6 & 0.88 & 15 & 4.92 \\
\hline 7 & Pink eye & 3 & 0.40 & 7 & 2.30 \\
\hline 8 & Mange & 21 & 3.07 & 13 & 4.26 \\
\hline 9 & Fascioliasis & 57 & 8.35 & 4 & 1.31 \\
\hline 10 & Paramphistomiasis & 13 & 1.90 & 10 & 3.28 \\
\hline 11 & Gastrointestinal Nematodiasis & 109 & 15.96 & 45 & 14.75 \\
\hline 12 & Ectoparasitism & 47 & 6.88 & 25 & 8.20 \\
\hline 13 & Humpsore & 19 & 2.78 & 5 & 1.64 \\
\hline 14 & Foot and Mouth Disease & 18 & 2.64 & 0 & 0 \\
\hline 15 & Bovine Ephemeral Fever & 19 & 2.78 & 0 & 0 \\
\hline 16 & Black Quarter & 6 & 0.88 & 0 & 0 \\
\hline 17 & Papillomatosis & 9 & 1.32 & 0 & 0 \\
\hline 18 & Peste des Petits Ruminants & 0 & 0 & 15 & 4.92 \\
\hline 19 & Tetanus & 1 & 0.15 & 3 & 0.98 \\
\hline 20 & Mastitis & 29 & 4.25 & 7 & 2.30 \\
\hline 21 & Skin Disease & 25 & 3.66 & 3 & 0.98 \\
\hline \multicolumn{2}{|c|}{ Sub-total Medical Cases } & 593 & 86.82 & 291 & 95.41 \\
\hline \multicolumn{6}{|c|}{ Gynaeco-obstetrical Cases } \\
\hline 22 & Retained Placenta & 18 & 2.64 & 1 & 0.33 \\
\hline 23 & Repeat Breeder & 13 & 1.90 & 0 & 0 \\
\hline 24 & Anoestrous & 8 & 1.17 & 0 & 0 \\
\hline Sub & tal Gynaeco-obstetrical Cases & 39 & 5.71 & 1 & 0.33 \\
\hline \multicolumn{6}{|c|}{ Surgical Cases } \\
\hline 25 & Abscess & 19 & 2.78 & 1 & 0.33 \\
\hline 26 & Myiasis & 9 & 1.32 & 5 & 1.64 \\
\hline 27 & Navel ill & 11 & 1.61 & 2 & 0.66 \\
\hline 28 & Gid Disease & 0 & 0 & 4 & 1.31 \\
\hline 29 & Urolithiasis & 5 & 0.73 & 0 & 0 \\
\hline 30 & Overgrown Hoof & 7 & 1.02 & 0 & 0 \\
\hline 31 & Castrational Complication & 0 & 0 & 1 & 0.33 \\
\hline \multicolumn{2}{|c|}{ Sub-total Surgical Cases } & 51 & 7.47 & 13 & 4.26 \\
\hline \multicolumn{2}{|c|}{ Overall Cases } & 683 & 69.13 & 305 & 30.87 \\
\hline
\end{tabular}

(Rahman et al., 2012). This condition can be varied due to seasonal variation. Mainly, during winter season the prevalence of pneumonia may increase. Corneal opacity in cattle and goats were recorded $0.4 \%$ and $2.3 \%$ under medicinal group (Table 1). Other observation reported $1.9 \%$ and $9.9 \%$ cases of corneal opacity in cattle and goats, respectively (Rahman et al., 2012). Mange was recorded in $3.07 \%$ cattle and $4.26 \%$ goats (Table 1 ) that 
Table 2. Comparison based on sex of Cattle and Goats under the categorized group.

\begin{tabular}{lcccccc}
\hline \multirow{2}{*}{ Cases } & \multicolumn{3}{c}{ Cattle } & \multicolumn{3}{c}{ Goats } \\
\cline { 2 - 7 } & Total & Male\% & Female\% & Total & Male\% & Female\% \\
\hline Medical & 593 & $53.29(316)$ & $46.71(277)$ & 291 & $54.30(158)$ & $45.70(133)$ \\
Gynaeco-obstetrical & 39 & - & $100.00(39)$ & 1 & - & $100.00(1)$ \\
Surgical & 51 & $56.86(29)$ & $43.14(22)$ & 13 & $61.54(8)$ & $38.46(5)$ \\
Total & 683 & $50.51(345)$ & $49.49(338)$ & 305 & $54.43(166)$ & $45.57(139)$ \\
\hline
\end{tabular}

varies greatly with the report recorded as $0.33 \%$ in cattle and $2.11 \%$ in goats (Samad, 2001). However, Demodectic mange in cattle (Samad et al., 1979; Nooruddin and Rahman, 1985), Psoroptic mange in goat (Rahman et al., 1978) has been reported in Bangladesh. The prevalence of different parasitic infestations was recorded considerable in both species of ruminants. The most frequent case is gastrointestinal nematodiasis $15.96 \%$ in cattle and $14.75 \%$ in goats. Besides, $8.35 \%$ and $1.31 \%$ Fascioliasis, $1.9 \%$ and $3.28 \%$ Paramphistomiasis, $6.88 \%$ and $8.20 \%$ Ectoparasites, $2.78 \%$ and $1.64 \%$ Humpsore in cattle and goats, respectively (Table 1). The parasitic infestations are high in local areas in Bangladesh because animals are grazed beside roads, wetlands following traditional methods of rearing (Akter et al., 2011). Footand-mouth disease (FMD) was recorded $2.64 \%$ cases in cattle (Table 1). Comparatively higher prevalence in cattle has been reported in some studies as $5.71,8.58$ and $5.78 \%$ for Rahman et al. (1972), Sarker et al. (1999) and Rahman et al. (1999) respectively. Black quarter (BQ) was recorded $0.88 \%$ in cattle (Table 1). Analogous observations reported $0.31,0.46$ and $0.23 \%$ incidence of BQ in cattle (Rahman et al., 1972; Rahman et al., 1999 and Samad, 2001 respectively). However, the incidence of $B Q$ in cattle from different geographical locations in Bangladesh reported $0.04 \%$ (Haque et al., 1988). Papillomatosis was recorded $1.32 \%$ cases in cattle (Table 1). However, the prevalence of warts in cattle from Bangladesh reported $3.04 \%$ prevalence of warts under rural region (Nooruddin et al., 1986). Peste des Petits Ruminants (PPR) was recorded $4.92 \%$ cases in goats (Table 1). This finding supports the finding of $5.2 \%$ PPR cases in goats (Rahman et al., 2012). Tetanus is comparatively high in goats than cattle. This study recorded $0.15 \%$ cases of tetanus in cattle and $0.98 \%$ in goats (Table 1). The PPR cases recorded in this report is lower than $5.2 \%$ reported by Rahman et al. (2012) in goats. Mastitis $4.25 \%$ and $2.30 \%$ were diagnosed in cows and goat (Table 1) respectively. The prevalence of clinical mastitis of $2.12 \%$ was reported in dairy cattle by Islam et al. (2010). Some findings reported lower clinical mastitis of $0.37,0.89,0.65,0.71$ and $0.9 \%$ in cows (Nooruddin et al., 1986; Sarker et al., 1999; Rahman et al., 1999; Samad, 2001; Rahman et al., 2012, respectively). Though mastitis is a common disease in Bangladesh due to poor management of dairy farms, this condition can be varied due to regional variation.

\section{Gynaeco-obstetrical cases}

Retained placenta disorder was recorded in $2.64 \%$ cows and $0.33 \%$ does (Table 1 ). This report is slightly lower than $4.71 \%$ in cattle and $6.25 \%$ in goats reported by Lucky et al. (2016) but higher than $0.37 \%$ and $0.50 \%$ in cows reported by Rahman et al. (1999) and Samad (2001), respectively. This condition occurs due to dirty cattle shed which may lead to early infection of the placenta responsible for inflammation and hence delay or reduced changes of placental separation and expulsion. Repeat breeding was recorded in $1.90 \%$ cattle and there was no case found in goats (Table 1). However, the reported prevalence of repeat breeders in cows in Bangladesh varied from 5 to 20.2\% (Shamsuddin, 1995; Sarder et al., 2010). Anoestrous was estimated $1.17 \%$ in cattle but there was no case available in goats. Samad (2001) reported $0.86 \%$ in cattle and $0.47 \%$ in goats. Higher rate of prevalence $(23.52 \%$ in cattle and $31.25 \%$ in goats) was recorded by Lucky et al. (2016) at Sylhet Agricultural University area.

\section{Surgical cases}

The abscess was recorded in $2.7 \%$ cattle and $0.33 \%$ goats (Table 1). Rahman et al. (2012) reported $1.1 \%$ cattle and $1.3 \%$ goats affected with an abscess at Patuakhali Science and Technology University Veterinary Clinic, Babugonj, Barisal. Myiasis was recorded in $1.32 \%$ cattle and $1.64 \%$ goats (Table 1). Maggot-infested wounds have been reported in cattle 1.07\% (Nooruddin et al., 1986) and $2.20 \%$ (Das and Hashim, 1996) from Bangladesh. Myiasis prevalence was reported higher $(11.0 \%$ in cattle) which is similar to the report of Rahman et al. (1972). Navel-ill was recorded only in $1.61 \%$ calves and 0.66 kids (Table 1 ). This finding supports the $0.79 \%$ and $0.62 \%$ navel-ill cases in calves and kids, respectively recorded by Samad (2001). Gid disease was recorded in goat 1.31\% (Table 1). Previous studies recorded $5.38 \%$ (Samad, 2001) and $2.5 \%$ (Rahman et al., 2012) gid disease in goats. 
Urolithiasis recorded was scanty in this study, $0.73 \%$ in cattle and no case was found in goats (Table 1). However, obstructive urolithiasis in cattle reported very low percentage, $0.02 \%$ (Samad, 2001) and 1.1\% (Rahman et al., 2012). Overgrown hoofs were recorded only in $1.02 \%$ cattle during this study period but non in goats (Table 1). Prevalence of overgrown hoofs reported $1.12 \%$ in cattle by Nooruddin et al. (1986). But another study estimated $0.02 \%$ cases of overgrown hoofs in cattle and $0.70 \%$ in goats (Samad, 2001). Although a huge number of the animal visit for castration at the veterinary hospital, just only one case of complication after castration was found in this study. The prevalence was $0.33 \%$ in case of goats.

\section{Conclusion}

The present study gives the scenario of diseases and disorders in the particular study area. Parasitic infestation is the most prevalent disease state in the region. Along with this, digestive disorder and fever with unknown etiology were also found dominant. Regular anthelmintic therapy is therefore necessary to achieve control of parasitic infestations to avoid economic hazards. Moreover, hygienic management and feeding practices can develop the health status of animals from digestive disorders. The obtained knowledge from this study would help for the future identification and characterization of several etiological agents of various diseases as well.

\section{ACKNOWLEDGMENT}

The author expresses his deepest sense of gratitude to Veterinary Surgeon, Beanibazar, Sylhet for his scholastics guidance and inspiration during the study period and preparing this report.

\section{CONFLICTS OF INTEREST}

The authors declare no conflicts of interest.

\section{REFERENCES}

Akter, Y., Uddin, M. M., Islam, M. N., \& Khatun, M. A. (2011). Prevalence of Gastrointestinal Parasitism in Dairy Cattle in MuktagachaUpazila of Mymensingh District, Bangladesh Bangladesh Research Publication Journal, 5, 376-380.

Alam, M. A., Amin, M. R., Paul, T. K., Saha, T. K., Rahman, M. K., \& Rizon, M. K. (2015). Prevalence of clinical diseases and disorders of goats at Upazila Livestock Development Center, Kapasia, Gazipur. Asian Journal of Medical and Biological Research, 1(1), 47-52.

Das, B. C., \& Hashim, M. A. (1996). Studies on surgical affections in calves. Bangladesh Veterinary Journal, 30, 53-57.

Haque, M. E., Samad, M. A., \& Rahman, A. (1988). Epizootiology investigation of Black quarter in cattle of Bangladesh. Bangladesh Veterinarian, 5, 10-13.

Hoque, M. S., \& Samad, M. A. (1996). Prevalence of clinical diseases in dairy cross-bred cows and calves in the urban areas in Dhaka. Bangladesh Veterinary Journal, 30, 118-129.

Hoque, M. S., \& Samad, M. A. (1997). Present status of clinical diseases of goats in the urban areas in Dhaka. Bangladesh Veterinary Journal, 31, 35-40.

Kabir, M. H., Reza, M. A., Razi, K. M. A., Parvez, M. M., Bag, M. A. S., \& Mahfuz, S. U. (2010). A report on clinical prevalence of diseases and disorders in cattle and goat at the Upazilla Veterinary Hospital, Ulipur, Kurigram. International Journal of Biological Research, 2, 17-23.

Lucky, N. S., Hossain, M. K., Roy, A. C., Haque, M. M., Uddin, A. H. M. M., Islam, M. M., \& Howlader, M. M. R. (2016). A longitudinal study on clinical diseases and disorders of cattle and goats in Sylhet, Bangladesh. Journal of Advanced Veterinary and Animal Research, 3(1), 24-37.

Nooruddin, M., \& Rahman, M. S. (1985). A note on bovine demodicosis in Bangladesh. Indian Journal of Veterinary Medicine 5, 139-140.

Nooruddin, M., Sarker, A. J., Baki, M. A., Ali, M. R., Dey, A. S., \& Hoque, M. F. (1986). Prevalence of diseases of external organs of cattle. Bangladesh Veterinary Journal, 20, 11-16.

Osmani, A. B. M. M. G., Hossain, M. A., Rahman, M. M., \& Alam, M. R. (2000). Corneal opacity in cattle: Prevalence and therapeutic evaluation of certain drugs. Bangladesh Veterinarian, 17, 42-45.

Pallab, M. S., Ullah, S. M., Uddin, M. M., \& Miazi, O. F. (2012). A cross sectional study of several diseases in cattle at ChandanaishUpazilla of Chittagong district. Scientific Journal of Veterinary Advances, 1, 28-32.

Pharo, H. J. (1987). Analysis of clinical case records from dairy co-operatives in Bangladesh. Tropical Animal Health and Production 19, 136-142.

Prasad, J., Uoshi, S. V., \& Rekib, A. (1980). Studies on the clinico-pathics of grazing animals in tropics - corneal opacity syndrome. Indian Veterinary Journal, 57, 310-315.

Rahman, A., Samad, M. A., \& Huq, M. M. (1978). Clinicopathological studies on psoroptic mange in a goat. Bangladesh Veterinary Journal, 13, 53-55.

Rahman, M. A., Ali, K. M., \& Rahman, A. (1972). Incidence of diseases of cattle in Mymensingh. Bangladesh Veterinary Journal, 6, 25-30.

Rahman, M. A., Islam, M. A., Rahman, M. A., Talukder, A. K., Parvin, M. S., \& Islam, M. T. (2012). Clinical diseases of ruminants recorded at the Patuakhali Science and Technology University Veterinary Clinic. Bangladesh Journal of Veterinary Medicine, 10(1\&2), 63-73.

Rahman, M. M., Ali, M., \& Hashem, A. (1999). Livestock disease problems in a selected area of Sherpur district. Bangladesh Journal of Training and Development, 12, 205-210.

Rosenberger, G. (1979). Clinical Examination of Cattle. 2nd edn., Verlag Poul Parey, Germany.

Samad, M. A. (2001). Observations of clinical diseases in ruminants at the Bangladesh Agricultural University Veterinary Clinic. Bangladesh Veterinary Journal, 35, 93-120.

Samad, M. A., Bari, A. S. M., \& Bashar, S. A. (1988). Gross and histopathological studies on bovine babesiosis in Bangladesh. Indian Journal of Animal Science 58, 926-928.

Samad, M. A., Islam, M. A., \& Hossain, A. (2002). Patterns of occurrence of calf diseases in the district of Mymensingh in 
Bangladesh. Bangladesh Veterinary Journal, 36, 1-5.

Samad, M. A., Rahman, A., \& Hossain, M. I. (1979). Studies on Demodectic mange in cattle. Bangladesh Journal of Scientific Research, 2, 7-13.

Sarder, M. J. U., Moni, M. I. Z, \& Aktar, S. (2010). Prevalence of reproductive disorders of cross breed cows in the Rajshahi district of Bangladesh. SAARC Journal of Agriculture, 8, 65-75.

Sarker, M. A. S., Hashim, M. A., Rahman, M. B., \& Begum, H. (1999). Studies on bovine lymphadenitis syndrome. Bangladesh Veterinarian, 10, 6-8.
Shamsuddin, M. (1995). Fertility trend and status of oestrus detection in the bovine under farm conditions in Bangladesh. Bangladesh Veterinary Journal, 29, 9-16.

Sutradhar, B. C., Hossain, M. A., \& Alam, M. R. (2000). Incidence of bloat and it response to certain drugs in cattle. Bangladesh Veterinarian, 17, 37-41. 